\title{
Little Clinical Relevance of Ca125, Cea and Ca125/Cea Ratio for the Differential Diagnosis of Ovarian and Non- Ovarian Carcinomatosis
}

Carmen Manuela Tauste Rubio

Gynecology and Obstetrics in the Navarre Health System - Osasunbidea, university of Barcelona, Spain.

Corresponding author: Carmen Manuela Tauste Rubio, Gynecology and Obstetrics in the Navarre Health System - Osasunbidea, university of Barcelona, Spain

Received date: May 12, 2021; Accepted date: May 28, 2021; Published date: June 17, 2021

Citation: Carmen Manuela Tauste Rubio (2021) Little Clinical Relevance of Ca125, Cea and Ca125/Cea Ratio for the Differential Diagnosis of Ovarian and Non- Ovarian Carcinomatosis. J. Women Health Care and Issue. 4(6); DOI: 10.31579/2642-9756/064

Copyright: (c) 2021 Carmen Manuela Tauste Rubio, This is an open access article distributed under the Creative Commons Attribution License, which permits unrestricted use, distribution, and reproduction in any medium, provided the original work is properly cited.

\section{Abstract:}

Background: In women, peritoneal cancer is commonly associated to epithelial ovarian cancer. Ovarian peritoneal carcinomatosis patient survival appears to be better in comparison to other peritoneal Malignancies, e.g., colorectal neoplasms or mesotheliomas. Here, we aim to analyze the value of CA125, CEA, CA125/CEA ratio (CCR) tumor markers as preoperative tools for the diagnosis ovarian cancer.

Material and methods: From 2005-2008, we recruit prospectively patients admitted to the Navarre Hospital Complex Gynecologica service with peritoneal carcinomatosis and suspicion of ovarian cancer origins. The final diagnosis of ovarian cancer carcinomatosis or other malignancies was obtained through Biopsy or cytology. CA 125, CEA and CCR were determined from preoperative venous blood Samples. We compared the tumor markers values between groups of ovarian cancer carcinomatosis and non-ovarian cancer carcinomatosis and calculate the receiver operating curves (ROC) for CA 125, CEA and CCR.

Results: From 250 patients with suspicion of having ovarian peritoneal carcinomatosis, only $86.4 \%$ of the Cases were finally diagnosis of ovarian cancer. Sensitivities of CA125 > $35 \mathrm{mg} / \mathrm{dL}$, CEA < $5 \mathrm{ngr} / \mathrm{mL}$, and CCR > 25 were 95.5\%, 91.9\%, and 93.6\% with specificities of $4.6 \%, 40.9 \%$ and $40.0 \%$, respectively. ROC displayed poor performance for CA125 and CEA for detecting ovarian peritoneal carcinomatosis patients (area under the curve (AUC): 0.69 and 0.63, respectively) while ROC analysis of CCR showed better results (AUC: 0.74).

Conclusions: CCR is somehow useful to differentiate between ovarian and non-ovarian peritoneal carcinomatosis patients in comparison with CA125 and CEA alone, although without sufficient specificity for improving the differential diagnosis.

Keywords: ca125; cea; carcinomatosis; ovarian mass; ovarian tumor; ovarian cancer

\section{Introduction}

Epithelial ovarian cancer (EOC) represents $95 \%$ of all ovarian malignancies with the majority of patients in advanced-stage of the disease at presentation.[1] EOC encompasses the epithelial malignancies of ovaries, fallopian tubes and peritoneal primary site, due to their common pathogenic mechanisms. [2, 3] Peritoneal carcinomatosis (PC) is a late-stage manifestation of ovarian cancer, as well as of other malignancies such as colorectal or gastric cancers with different prognosis and treatment. $[4,5]$ To date, a confirmatory biopsy is mandatory for a definitive diagnosis of ovarian carcinomatosis.

Serum biomarkers may be useful to predict EOC diagnosis. Cancer antigen 125 (CA125) and the carcinoembryonic antigen (CEA) are routinely used in patients suspected of having ovarian cancer.[6] Although much research has been devoted to investigate these biomarkers, the reports usually refer to ovarian cancer in general with no differentiation between stages.

Serum CA125 glycoprotein level is the most widely studied biochemical screening method for ovarian cancer. The standard threshold is $35 \mathrm{mg} / \mathrm{dL}$.
Ovarian cancer raises CA125 50\% in stages I and II and up to $90 \%$ in stages III and IV [7]. Frequently, its concentration may rise in certain gynecological conditions, e.g., endometriosis, leiomyomas and pelvic inflammatory disease, as well as in other non-gynecological disorders, such as hepatic cirrhosis and heart failure. Furthermore, CA125 values may be elevated in $1 \%$ of the normal population [8]. In 2000, Meyer et al. showed that $82 \%$ of subjects with ovarian cancer and $28 \%$ of patients with non-gynecological cancers (including pancreatic, breast, and colon cancers) have increased CA125 levels. [8]

The CEA is normally produced in fetal tissue; however, it may also be synthesized in certain type of carcinomas. Serum concentrations exceeding $5 \mathrm{ng} / \mathrm{ml}$ are often found in patients with colorectal, gastric, breast or lung cancer, as well as in certain types of gynecological tumors. Furthermore, elevated CEA concentrations may associate with infection, pancreatitis, hepatic cirrhosis and some benign tumors. In colorectal cancer, CEA values above $20 \mathrm{ng} / \mathrm{ml}$ have clinical relevance because of the relationship with metastasis [8]. Serum CEA is elevated in approximately $35 \%$ of all ovarian cancer patients and occurs more often in mucinous tumors $(88 \%)$ than in serous ones $(19 \%)$ [9]. 
Tests with CA125/CEA ratio (CCR) have been carried out aiming to differentiate ovarian cancers from non-ovarian cancers in pelvic masses. [9] However, no special consideration was given to tumor stage or load. In 1990, Buamah et al published a study with 155 patients who had elevated CA125 concentrations from which 47 patients had been diagnosed ovarian cancer, 38 colorectal cancer, 24 cervical cancer, 17 gastric cancer, and 9 pancreatic cancer. [10] The authors report that a CA125/CEA ratio above 25 may be used as a tool to differentiate ovarian cancer from the other diagnoses. Yedema et al in 1992 studied the CCR in 47 cases of advanced EOC and 24 cases of colorectal cancer. A CA125/CEA ratio over 25 showed $91 \%$ sensitivity and $100 \%$ specificity for detecting CCR ovarian cancer. [11] In 2011, Sørensen et al. published a trial with 640 patients (ovarian laboratory investigation). In this population, malignant diagnosis was confirmed in 355 subjects: 248 ovarian tumors and 107 non-ovarian tumors. The outcomes improved with CCR in comparison with CA125 or CEA alone, achieving a specificity of $86 \%$ when the cut-off value was increased from 25 to 100 . [12] It is remarkably that EORTC-55971 trial in 2011, led by Ignace Vergote, used CCR higher than 25 as one of the criteria for patient recruitment.

In the present study, we aim to analyze the value of our routine tumor markers CA125 and CEA and the CCR as preoperative tools to differentiate between ovarian and non-ovarian primary cancer in patients with carcinomatosis.

\section{Material and Methods:}

Between January 2005 and December 2016, we recruited 250 patients who were admitted to the Navarre Hospital Complex (Spain) Department of Gynecologic Oncology with suspicion of ovarian carcinomatosis. We prospectively identified and registered all of these women in a database designed specially to assess the diagnostic process. Recruitment criteria were radiological suspicion of peritoneal surface malignancy through computed tomography scans [13] or surgical procedure and final pathological diagnosis. As the recruitment was prospective, the EOC patients without carcinomatosis were not included. In all suspicious patient we requested the serum tumor markers prior the main treatment per protocol.[6] After pathologic or cytologic study, the diagnostic of non- malignant disease of peritoneum was the single exclusion criteria.

Tumor marker blood tests were performed during the diagnostic procedure. Age, Main Symptom and Performance status (PS) data as the ECOG-PS scale were collected at the beginning of the diagnosis. [14]

We generated descriptive statistics for all the measurements: means, ranges, and standard deviations for continuous variables, and frequencies and proportions for categorical data. Continuous variables were compared using Student's t-test and categorical variables using the Chi-squared. Patient survival was calculated applying the Kaplan Meier method using the date of the diagnosis until a known date of follow-up evaluation or date of death. Receiver operating characteristics (ROC) analysis was used to estimate specificity and sensitivity. The resulting area under the curve (AUC) indicates the average sensitivity of a marker over the entire ROC curve for ovarian PC versus non-ovarian PC. ROC analysis was plotted to examine optimal cut-off values that maximized the sum of sensitivity and 1-specificity. A p value $<0.05$ was considered a statistically significant difference. Statistical analysis was performed with the SPSS statistical software package, version 25.0 (SPSS Inc., Chicago, IL, USA).

\section{Results}

From the 250 patients admitted to the hospital suspected of having carcinomatosis, the final diagnostic technique was biopsy in $93.6 \%$ and cytology in $6.4 \%$ of the cases. We diagnosed $216(86.4 \%)$ epithelial ovarian, tube or peritoneal cancers, 33 (13.2\%) non-ovarian carcinomatosis and one peritoneal tuberculosis $(0.4 \%)$ which were excluded from the study. Non-ovarian carcinomatosis had a wide diversity of origins: uterus in six patients, appendix in six, mesothelioma in four, pancreas in four, colon and rectum in three, small bowel in two, gastric in two, lungs in two, and miscellaneous in the remaining six patients (Figure 1).

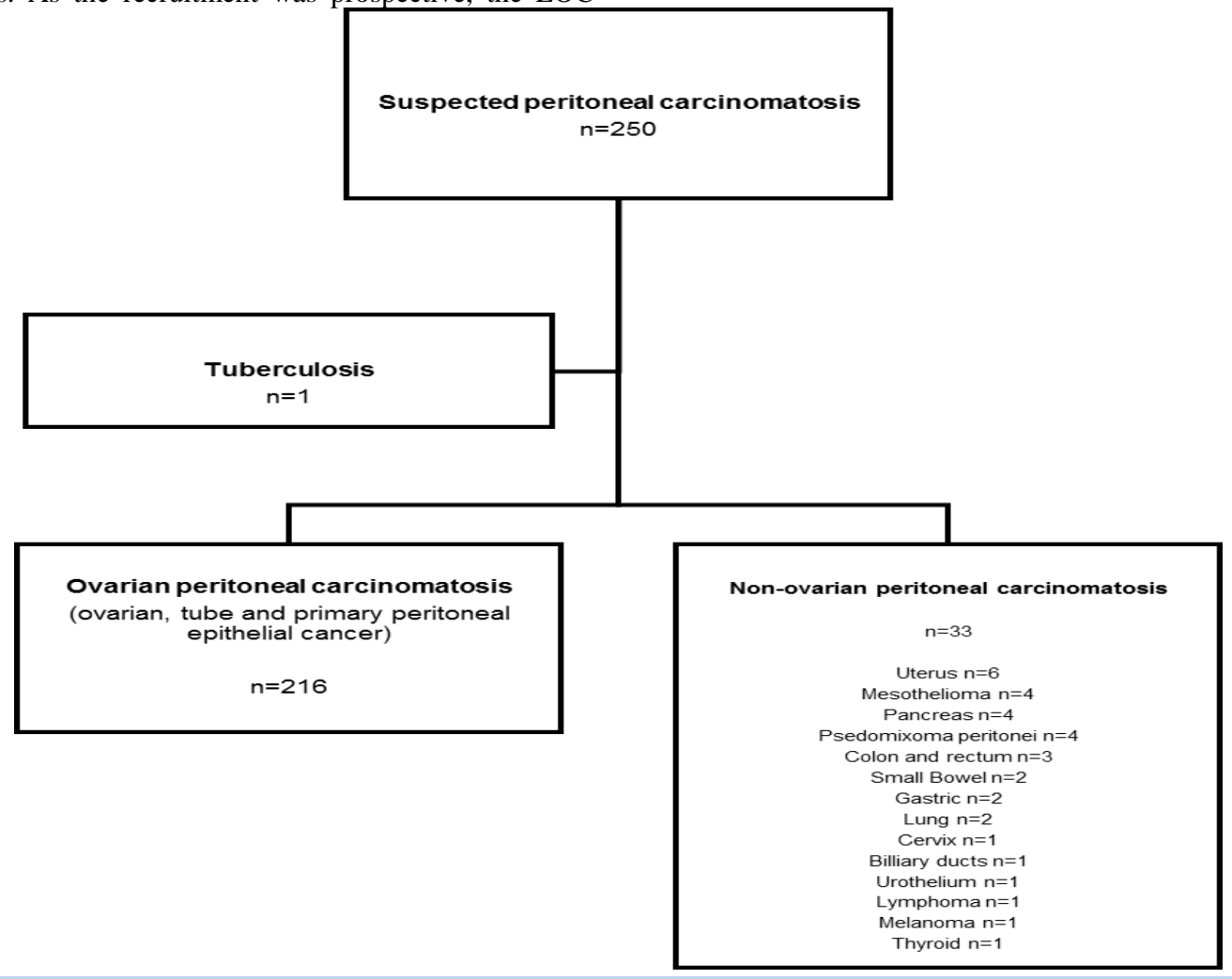

Figure 1: Flow-chart of patients suspected of having ovarian peritoneal carcinomatosis 
Patients in advanced stages of the ovarian cancer showed longer survival (OS 32 months CI 95\%25.79 - 39.72) than carcinomatosis of other origins (OS 5.52 months CI 95\% (0.00 - 11.2)) (Figure 2).

The demographic and clinical characteristics of the patients with ovarian and non-ovarian PC was similar, showing no significant differences regarding age and main baseline symptoms. However, the performance status (PS) measured using the ECOG-PS scale showed significant differences with better PS in ovarian PC patients (Table 1).

\begin{tabular}{|c|c|c|c|c|}
\hline & & $\begin{array}{l}\text { Ovarian } \\
\text { carcinomatosis }\end{array}$ & $\begin{array}{l}\text { Non-ovarian } \\
\text { carcinomatosis }\end{array}$ & p-value \\
\hline $\mathrm{N}$ & & 216 & 33 & \\
\hline Age & & $\begin{array}{l}64.66(+/- \\
12.06)\end{array}$ & $\begin{array}{l}64.31(+/- \\
14.7)\end{array}$ & n.s. \\
\hline \multirow{2}{*}{$\begin{array}{l}\text { ECO-PS } \\
(\%)\end{array}$} & $0-2$ & 88.02 & 72.73 & \multirow[t]{2}{*}{$\mathrm{P}<0.05$} \\
\hline & $3-4$ & 11.98 & 27.27 & \\
\hline \multirow{5}{*}{$\begin{array}{l}\text { Main } \\
\text { symptom } \\
(\%)\end{array}$} & $\begin{array}{l}\text { Abdominal } \\
\text { pain }\end{array}$ & 37.26 & 25.0 & \multirow[t]{5}{*}{ n.s. } \\
\hline & $\begin{array}{l}\text { Abdominal } \\
\text { distension }\end{array}$ & 16.50 & 28.12 & \\
\hline & Asymptomatic & 15.56 & 25.0 & \\
\hline & $\begin{array}{l}\text { Intestinal } \\
\text { occlusion }\end{array}$ & 3.30 & 9.30 & \\
\hline & other & 27.38 & 12.58 & \\
\hline
\end{tabular}

Table 1: Epidemiological and clinical characteristics of subjects with ovarian and non-ovariancarcinomatosis (data are presented as means \pm SD or $\%$ when stated)

CA125 concentrations were significantly higher in patients with ovarian PC (mean value $1,434.34 \mathrm{mg} / \mathrm{dL}$ ) in comparison to non-ovarian PC patients (mean value $340.30 \mathrm{mg} / \mathrm{dL}$ ) (mean difference $1,094.04 \mathrm{mg} / \mathrm{dL}$, CI $312.14-1875.93, \mathrm{p}<0.05)$. Contrarily, CEA levels were lower for the ovarian PC group (mean value $3.9 \mathrm{ng} / \mathrm{mL}$ ) in comparison to the non- ovarian PC group (mean value $29.57 \mathrm{ng} / \mathrm{mL}$ ) (mean difference 25.64 $\mathrm{ng} / \mathrm{mL}, \mathrm{CI} 12.88-38.42, \mathrm{p}<0.05)$. Thus, CCR was higher in patients with ovarian PC with a mean value of 2,299.19, while non-ovarian PC patients showed a mean value of 265.57 (mean difference $2,033.61, \mathrm{CI}=1,086.70$ - 2,980.51 p < 0.05) (Table 2.Figure 2).
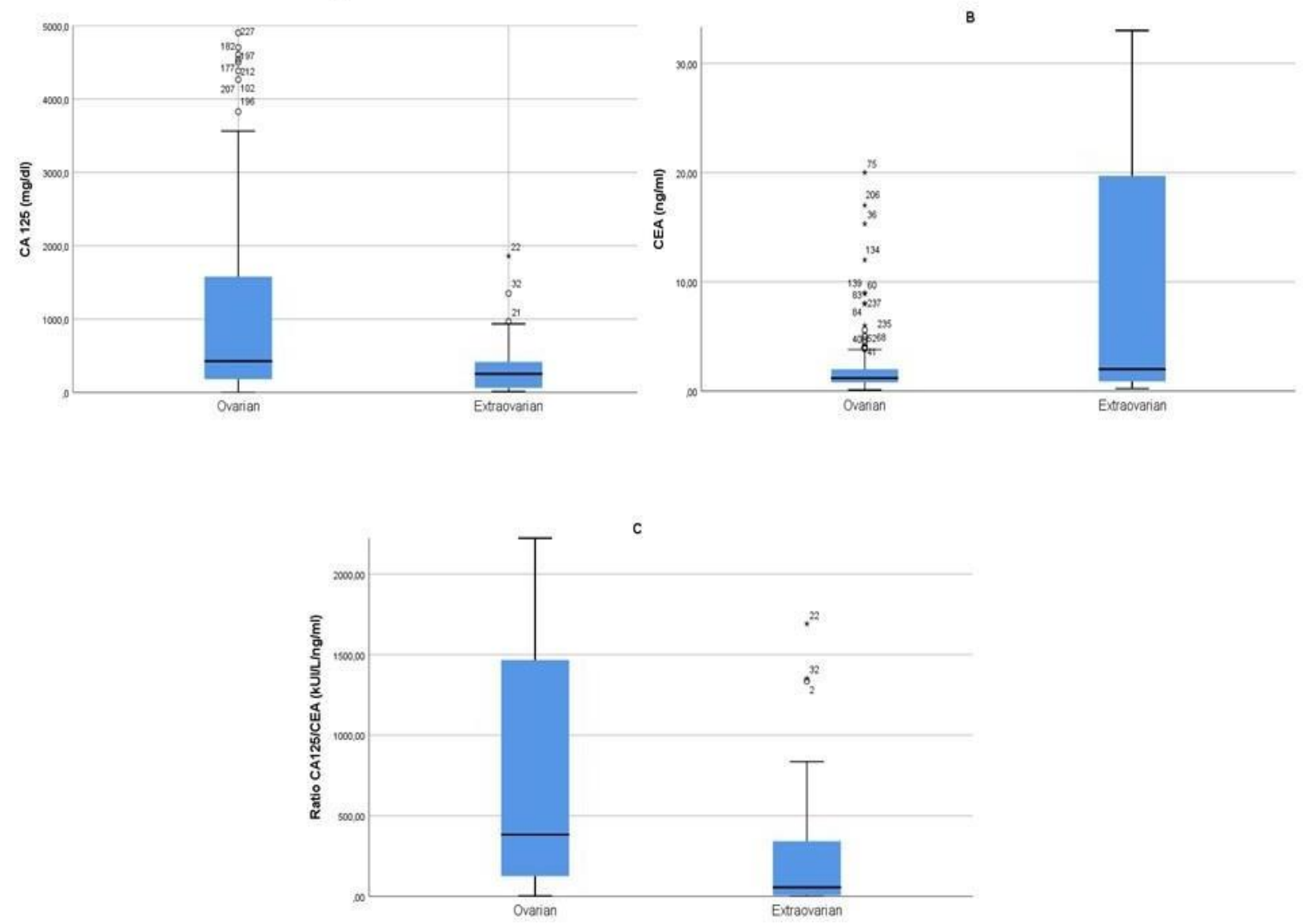
The conventional $>35 \mathrm{mg} / \mathrm{dL}$ threshold value for CA-125 was obtained in $95.5 \%$ of ovarian PC patients and $63.6 \%$ of non-ovarian PC subjects, while CEA levels $<5 \mathrm{ng} / \mathrm{ml}$ were found in $91.9 \%$ of ovarian malignancies and $59.1 \%$ of non-ovarian malignancies. CCR $>25 \mathrm{pg} / \mathrm{mL}$ was Determined in 93.6\% of ovarian PC and $60.0 \%$ of non-ovarian PC. In the search to increase the specificity above $70 \%$, the cut-off levels were changed to CA125 > $360 \mathrm{mg} / \mathrm{dL}, \mathrm{CEA}<1 \mathrm{ng} / \mathrm{Ml}$ and CCR > 250 with a decline in sensitivity $(53.4 \%, 30.2 \%$ and 55.5\%, respectively) (Table 2).

\begin{tabular}{|c|c|c|c|c|}
\hline & $\begin{array}{c}\text { Ovarian } \\
\text { carcinomatosis }\end{array}$ & $\begin{array}{c}\text { Non-ovarian } \\
\text { carcinomatosis }\end{array}$ & Difference & $p$-value \\
\hline $\mathrm{CA} 125(\mathrm{mg} / \mathrm{dL})$ & $1,434.34$ & 340.30 & $\begin{array}{l}1,094.04 \\
(\mathrm{CI}=312.14-1,875.93)\end{array}$ & $<0.012$ \\
\hline CEA (ng/mL) & 3.9 & 29.57 & $\begin{array}{l}25.64 \\
(\mathrm{CI}=12.88-38.42)\end{array}$ & $<0.01=$ \\
\hline CA125/CEA ratio & $2,299.19$ & 265.57 & $\begin{array}{l}2,033.61 \\
(\mathrm{CI}=1,086.70-2,980.51)\end{array}$ & $<0.012$ \\
\hline
\end{tabular}

Table 2: Serum tumor markers CA125 and CEA, CA125/CEA ratio (data are presented as means, differences with CI)

\begin{tabular}{|c|c|c|c|c|}
\hline & $\begin{array}{l}\text { Ovarian } \\
n=216\end{array}$ & $\begin{array}{l}\text { Non-ovarian } \\
\mathrm{n}=33\end{array}$ & Sensitivity \% (CI) & Specificity \% (CI) \\
\hline $\mathrm{CA} 125>35 \mathrm{mg} / \mathrm{dL}^{\dagger}$ & 153 & 21 & $95.5(90.5-97.5)$ & $4.6(0.8-21.8)$ \\
\hline $\begin{array}{l}\text { CA125 } \\
>360 \mathrm{mg} / \mathrm{dL}_{\mathrm{\alpha}}^{\dagger}\end{array}$ & 86 & 6 & $53.4(45.7-61.0)$ & $72.7(51.9-86.9)$ \\
\hline $\mathrm{CEA}<5 \mathrm{ng} / \mathrm{mL}^{\ddagger}$ & 137 & 13 & $91.9(86.5-95.3)$ & $40.9(23.3-61.3)$ \\
\hline $\mathrm{CEA}<1 \mathrm{ng} / \mathrm{mL}^{*}$ & 45 & 5 & $30.2(23.4-38.0)$ & $77.3(56.6-89.9)$ \\
\hline $\mathrm{CCR}>25^{*}$ & 189 & 18 & $93.6(89.3-96.2)$ & $40.0(24.6-57.7)$ \\
\hline $\mathrm{CCR}>250^{\star}$ & 82 & 6 & $55.0(47.0-62.8)$ & $72.7(51.8-86.8)$ \\
\hline \multicolumn{5}{|c|}{$\begin{array}{l}\text { CCR }=\text { CA125/CEA ratio; } \mathrm{CI}=95 \% \text { confidence interval } \\
\dagger \text { Data on } 183 \text { patients } \\
\ddagger \text { Data on } 171 \text { patients }\end{array}$} \\
\hline
\end{tabular}

Table 3: Conventional values and suggested new cut-offs for CA125, CEA, and CA125/CEA ratio for ovarian versus non-ovarian PC patients.

We assessed tumor marker performance in the identification of ovarian cancer and patient stratification through ROC Curves. CA125, CEA and CCR showed AUC of $0.65,0.63$ and 0.74 respectively. (Figure 3 )

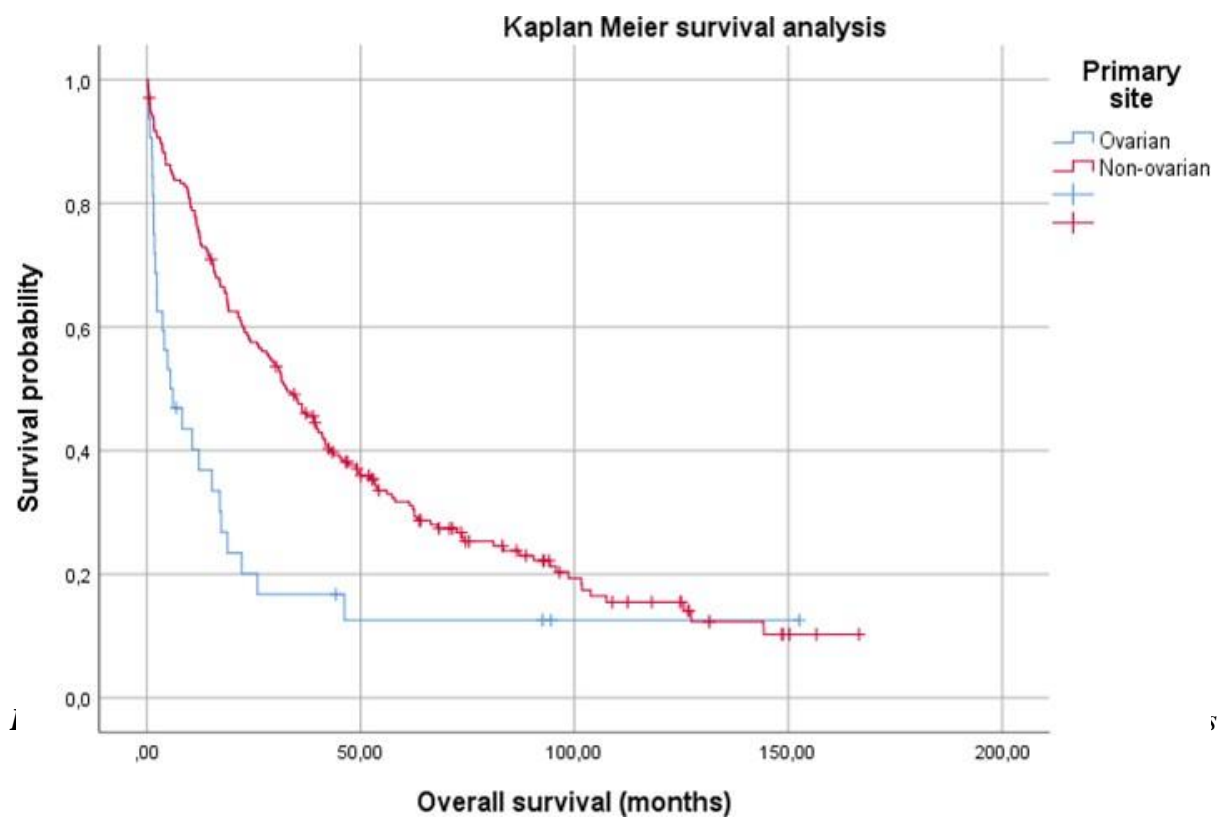



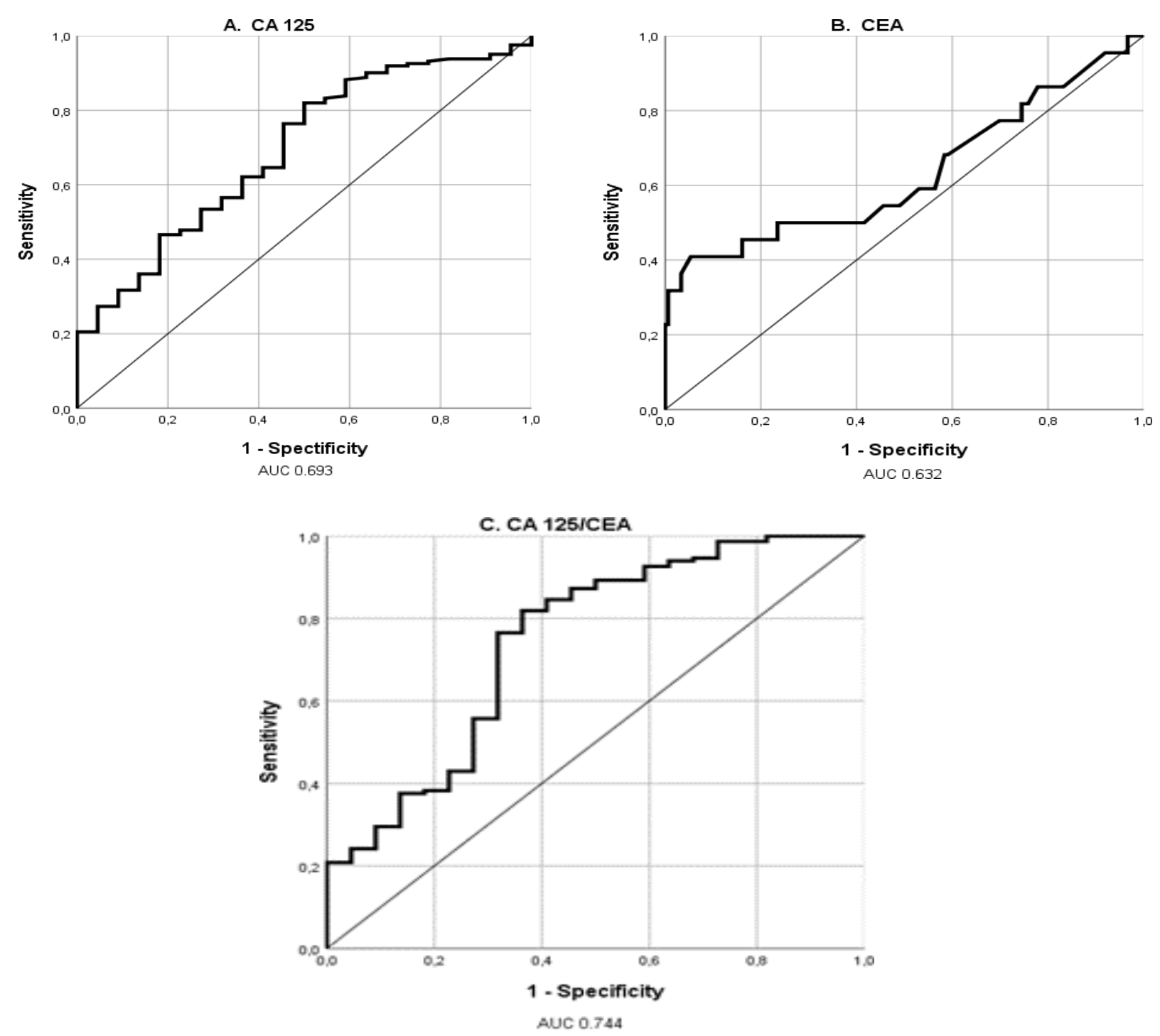

Figure 4: ROC curves and AUC for CA125, CEA and CA125/CEA ratio

\section{Discussion:}

Preoperative differentiation between ovarian and non-ovarian primary site PC is extremely important for a quality management. Despite the interest of a reliable and quick test in PC, CA 125, CEA and CCR showed poor performance to diagnose EOC.

Initially, the increase of CA125 with low CEA and the presence of an ovarian mass seemed suitable tools for predicting the origin of the PC. In fact, in the EORTC-55971 trial carried out by Ignace Vergote among the recruitment criteria was a fine-needle aspirate showing an adenocarcinoma and presence of a pelvic (ovarian) mass or a cancer antigen 125 (CA-125, KUI/mL) to carcinoembryonic antigen (CEA, $\mathrm{ng} / \mathrm{mL}$ ) ratio greater than 25 [14]. Despite these common criteria for suspecting ovarian PC, our clinical data are discouraging in this sense.

As other studies [10, 15], CA125 levels shows for ovarian PC are higher than in non-ovarian PC, although CA125 has not demonstrated preoperative with the classic cut-off $>35 \mathrm{mg} / \mathrm{dL}$. The increase in CA 125 threshold did not show better performance due to the consequent detriment of sensitivity. In addition, the ROC analysis represented a poor model for differentiating between ovarian and non-ovarian PC (Table 3, Figure 3A).

According to Høgdall et al., CEA does not seem useful for discarding non-ovarian malignancies because CEA is elevated in approximately 35\% in ovarian tumors, particularly in mucinous types. [16] In our series, CEA $<5 \mathrm{~mm}$ sensitivity is $91.9 \%$ but with a limited specificity of $40.9 \%$. Although, the ROC curve showed better performance than CA 125, AUC continued been poor to differentiate ovarian from non-ovarian PC patients (Figure 3.B).

CCR was designed to improve the performance of tumor markers for discriminating ovarian from non-ovarian malignancies. The studies by Buamah [10] and Yedema [11] showed a good accomplishment of CCR. Moro et al tested the role of CCR to identify the metastatic showed the low ability of CCR to distinguish between primary ovarian lesions from metastatic lesions.[17] Unlike Moro study, our sample is composed by patients with carcinomatosis, however the power of CCR as a discriminative test showed the ROC curve performance only has an acceptable AUC (0.74). The standard threshold described by the abovementioned authors (CCR > 25) shows low specificity (40.0\%). We 
modified the cut-off value in order to enhance the specificity, as was done by Sørensen et al. [12] in our case, we had to raise the threshold to 250 to achieve a specificity of $72.5 \%$, which caused an important decrease in the sensitivity (55\%). Considering these results, CCR is not an advantage for the routine management of patients suspected of having ovarian carcinomatosis in our environment. (Figure 3.C)

The importance of this study lies in clarifying which is the real diagnostic role of CA 125, CEA and CCR in the diagnostic of non-ovarian carcinomatosis. Some studies talk about the utility of this serum markers and its ratio referred to the ovarian tumor but not about the relevance of them in peritoneal carcinomatosis. [12, 17] In other studies, the CCR seems to be capital to diagnose non-ovarian peritoneal carcinomatosis [911]. In our series the relevance of CA 125, CEA or CCR are not as important to be diagnostic. The limitations of this study are in relation with the selection bias due to, as a gynecological service, we only admitted the patients with high suspicion of gynecological peritoneal malignancy. Maybe, the behavior of these tests could be different among the patients with peritoneal carcinomatosis in digestive service or internal medicine.

Because of the poor predictive value of our standard tumor markers or their ratio and the absence of prediction of ovarian tumor presence or its size, alternative tests should be considered in PC patients. Human epididymis protein (HE4) is highly sensitive for the diagnosis of ovarian cancer and higher specificity in comparison to the CA125. [18, 19]. Additional studies should be carried out to analyze the behavior of HE4 in non-ovarian tumors. Other novel techniques as differential scanning calorimetry (DSC), could become an excellent tool for diagnosis in PC. [20]

\section{Conclusions:}

The clinical origin of ovarian and non-ovarian PC is very similar. Our standard tumor markers CA125 and CEA and their ratio show statistically significantly differences between ovarian and non-ovarian PC. However, due to their low specificity, they have little clinical relevance to diagnose ovarian PC. Other preoperative tests may have better performance to predict the origin of PC.

\section{Conflicts Of Interest:}

Carmen M. Tauste, Jesús Zabaleta, Sara Aguirre, Antonio Llueca and Juan Carlos Muruzábal declare that they have no conflict of interest.

\section{Ethical Approval:}

This study was not supported by grant funding. All procedures performed in studies involving human participants followed the ethical standards of the institutional research committee and the 1964 Helsinki declaration and its later amendments or comparable ethical standards.

\section{Informed Consent}

Informed consent was not obtained for this retrospective study.

\section{References:}

1. Lheureux S, Gourley C, Vergote I, Oza AM. Epithelial ovarian cancer. Lancet [Internet].2019 Mar 23 [cited 2019 Jun 30];393(10177):1240-1253

2. Kurman RJ, Shih L-M. The Origin and Pathogenesis. Am J Surgery, 2011; 34(3):433-443.

3. Prat J, D'Angelo E, Espinosa I. Ovarian carcinomas: at least five different diseases with distinct histological features and molecular genetics. Hum Pathol [Internet]. 2018; 80:11-27

4. Chua TC, Liauw W, Saxena A, Al-Mohaimeed K, Fransi S, Zhao $\mathrm{J}$, et al. Evolution of locoregional treatment for peritoneal carcinomatosis: Single-center experience of 308 procedures of cytoreductive surgery and perioperative intraperitoneal chemotherapy. Am J Surg. 2011;

5. Implementación y desarrollo de un programa de tratamiento de la carcinomatosis peritoneal en Cataluña. Indicaciones y resultados clínicos con la técnica de Sugarbaker.2009;

6. Querlue D, Planchamp F, Chiva L, Fotopoulou C, Barton D, Cibula D. Ovarian Cancer Surgery Pocket Guidelines. Int J Gynecol Cancer. 2017;27(7):1534-1542.

7. Høgdall EVS, Christensen L, Kjaer SK, Blaakaer J, KjærbyeThygesen A, Gayther S, et al. CA125 expression pattern, prognosis and correlation with serum CA125 in ovarian tumor patients. From The Danish "MALOVA" Ovarian Cancer Study. Gynecol Oncol.2007;104 (3):508-515.

8. Meyer T, Rustin G. Role of tumour markers in monitoring epithelial ovarian cancer. $\mathrm{Br} \mathrm{J}$ Cancer [Internet]. 2000; 82(9):1535-1538.

9. Vergote I, Tropé CG, Amant F, Kristensen GB, Ehlen T, Johnson $\mathrm{N}$, et al. Neoadjuvant Chemotherapy or Primary Surgery in Stage IIIC or IV Ovarian Cancer. N Engl J Med.2010;

10. Buamah P k. Serum CA 12-5 Concentrations and CA 12.5/CEA Ratios in Patients with Epithelial Ovarian Cancer. J Surg Oncol. 1990; 44:97-99.

11. Yedema C. A. Use of Serum Tumor Markers in the Differential Diagnosis betwwn Ovarian and Colorectal Adenocarcinomas. Tumor Biol. 1992; 13 (18-26).

12. Sørensen SS, Mosgaard BJ. Combination of cancer antigen 125 and carcinoembryonic antigen can improve ovarian cancer diagnosis. Dan Med Bull [Internet]. 2011;58(11):A4331.

13. Laifer-Narin SL, Genestine WF, Okechukwu NC, Hecht EM, Newhouse JH. The Role of Computed Tomography and Magnetic Resonance Imaging in Gynecologic Oncology. PETClin [Internet]. 2018 Apr; 13(2):127-141.

14. Oken MM, Creech RH, Tormey DC, Horton J, Davis TE, McFadden ET, et al. Toxicity and response criteria of the Eastern Cooperative Oncology Group. Am J Clin Oncol [Internet]. 1982 Dec;5(6):649-655.

15. Choi JH, Sohn GS, Chay DB, Cho HB, Kim J-H. Preoperative serum levels of cancer antigen 125 and carcinoembryonic antigen ratio can improve differentiation between mucinous ovarian carcinoma and other epithelial ovarian carcinomas. Obstet Gynecol Sci. 2018; 61(3):344.

16. Høgdall EVS, Christensen L, Kjaer SK, Blaakaer J, Jarle Christensen I, Gayther S, et al. Protein expression levels of carcinoembryonic antigen (CEA) in Danish ovarian cancer patients: from the Danish "MALOVA"ovarian cancer study. Pathology [Internet]. 2008;40(5):487-492.

17. Moro F, Pasciuto T, Djokovic D, Di Legge A, Granato V, Moruzzi $\mathrm{MC}$, et al. Role of CA125/CEA ratio and ultrasound parameters in identifying metastases to the ovaries in patients with multilocular and multilocular-solid ovarian masses. Ultrasound Obstet Gynecol [Internet]. 2019 Jan 2;53(1):116-123.

18. Moore RG, McMeekin DS, Brown AK, DiSilvestro P, Miller MC, Allard WJ, et al. A novel multiple marker bioassay utilizing HE4 and CA125 for the prediction of ovarian cancer in patients with a pelvic mass. Gynecol Oncol. 2009;112(1):40-46.

19. Scaletta G, Plotti F, Luvero D, Capriglione S, Montera R, Miranda A, et al. The role of novel biomarker HE4 in the diagnosis, prognosis and follow-up of ovarian cancer: a systematic review. Expert Rev Anticancer Ther. 2017;17(9):827-839.

20. Garbett NC, Mekmaysy CS, Helm CW, Chaires JB. Differential scanning calorimetry of blood plasma for clinical diagnosis and monitoring. Exp Mol Pathol [Internet]. 2009 Jun 1 [cited 2019 Jul 8];86(3):186-191. 
* fast, convenient online submission

* rigorous peer review by experienced research in your field

* rapid publication on acceptance

* authors retain copyrights

* unique DOI for all articles

* immediate, unrestricted online access

At Auctores, research is always in progress.

Learn more www.auctoresonline.org/journals/women-health-care-andissues 